\title{
Designing An Ideal Model For Skill Laboratory Teaching And Learning In Developing Country, Lesson Learnt From Indonesian Medical School
}

\author{
Erike A. Suwarsono ${ }^{1}$, Riva Auda ${ }^{2}$ \\ Medical Education Unit, Department of Pediatric \\ Faculty of Medicine and Health Sciences \\ Syarif Hidayatullah State Islamic University \\ Jakarta, Indonesia \\ erike.suwarsono@uinjkt.ac.id
}

\author{
Dyah Ayu W Setyaningrum, \\ Faculty of Medicine \\ Trisakti University \\ Jakarta, Indonesia
}

\begin{abstract}
Skill laboratory teaching and learning is a part of medical school curriculum. The learning involves many things such as knowledge as well as affective and psychomotor capability, tutor role, and faculty financial support. In developing country, there is not only financial burden to support skill laboratory but also lack in number of qualified medical teacher. The aim was to develop the best model for skill learning in limited resources. The study developed through January-October 2016 and we analyzed the data quantitatively and qualitatively. For quantitative data we had gained from questionnaire and qualitative data were gained from written open question on how the skill learning process was going on in our faculty and participating observation during the process. The questionnaire was assessed students' and tutor's perspectives of 51 items using Likert scale, that questioning about the process, skill laboratory design, equipment, tutor role and student motivation. Total sample were 287 students and 25 tutors. The result was divided into three different domains that were students, tutor or building/equipment. Most of respondents said that the equipment including building support such as toilet, praying room was not in appropriate needs $(>75 \%)$. This result showed that both student and tutor want to have much better learning environment. There were limited manikin $(>70 \%)$, so the students find difficulties to do self-repetition. Students also noticed that tutor feedback were the best motivation for their self. The qualitative result also concluded that the capability of tutor in giving feedback and standardizing the skill could cover the gap in limited resources during the skill learning process. Making standardized video for all skill procedures is the alternative solution in lacking of manikin to self-practicing. Peer practices can also to be used in case of limited standardized patient. Based on our model, tutor is the central role to encourage the student in mastering the skill procedures.

Keywords : skill laboratory; teaching; learning
\end{abstract}

\section{INTRODUCTION}

Now days, medical education have been growing so fast, skill laboratory is a part of teaching and learning in medical school curriculum. Clinical skill laboratory is the place for teaching necessary competencies of being doctor [1]. The need of medical faculty to develop a best method in delivering clinical skill competencies is a determinant process in its curriculum. A student's ability to demonstrate proficiency in clinical procedure is considered as an important factor in curriculum of medical faculty [1.2]. In our faculty, clinical skill laboratory teaching and learning is a whole year process within module in all years of pre-clinical phase. As a new medical faculty that runs less than 12 years, our faculty still wants to evaluate the design of our clinical skill laboratory's curriculum. It is important to always review the clinical skill laboratory curriculum whether it is already fit the competencies or not, because in Indonesia every single medical student should pass the National Objective Structure in Clinical Examinations (OSCEs) as an assessment of their medical doctor's competencies. This study is a part of our evaluation program to enhance the clinical skill laboratory curriculum.

\section{METHOD}

The study was conducted in Medical Study Program of Faculty of Medicine and Health Sciences, Syarif Hidayatullah State Islamic University Jakarta, Indonesia through JanuaryOctober 2016. In our faculty, there is a unit called Clinical Simulation Unit (CSU) that has responsibility to develop any kind of clinical skill teaching and learning curriculum. This study was conducted within CSU monitory. We had developed instrument to measure quantitative and qualitative aspect, respectively. For quantitative data we had gained from questionnaire and qualitative data was gained from written open question on how the skill learning process was going on in our faculty and participating observation during the skill laboratory learning process. The questionnaire was assessed students' and tutor's perspectives of 51 items using Likert scale, that questioning about the process, skill laboratory design, equipment, tutor role and student motivation. Total sample were 287 students from year 1 to year 3 (pre-clinical year only) and 25 tutors. The result was divided into three different domains that were belonging to students', tutor's or building/equipment's domain.

From those quantitative and qualitative data, we make a deep analyzes and try to describe all of the problems that had been found in the result. We develop a model to assess what are the dominant problems that had already found based on the 
data. Thus, it will be use as guidance model to nurture and restructure the clinical skill teaching and learning curriculum.

\section{RESULT}

From total 312 respondents, most of them said that the facilities including building support such as toilet, praying room was not in appropriate needs $(>75 \%)$. This result showed that both student and tutor want to have much better facilities to optimize learning environment. There were limited manikin $(>70 \%)$, so the students find difficulties to do self-repetition. Students also noticed that tutor feedback were the best motivation for their self. The qualitative result also concluded that the capability of tutor in giving feedback and standardizing the skill could cover the gap in limited resources during the skill learning process. Making standardized video for all skill procedures is the alternative solution in lacking of manikin to self-practicing. Peer practices can also to be used in case of limited standardized patient.

We had analyzed the respond and make them into a list of problem's model. This model is shown in Fig. 1. In the Fig. 1, we can see the main issues in skill laboratory teaching and learning of our faculty. There are 4 main issues, two of them belong to equipment, building and resources and the last two belong to teaching and learning instrument that are video and manikin.

In the Fig. 2, we can conclude the evaluation of tutor's role, what was already good and what should improve. From Fig. 2, the good thing about tutor is giving feedback. This feedback has become major influence in student's learning process as most of them said that tutor's feedback had motivated them to become better learner. Although, there are some tutors need punctuality improvement and should always care to use many kind of learning's instrument includes video.

Based on those result on both Figure we are develop a recommendation model (Fig. 3) to our faculty to implement better clinical skill laboratory learning.

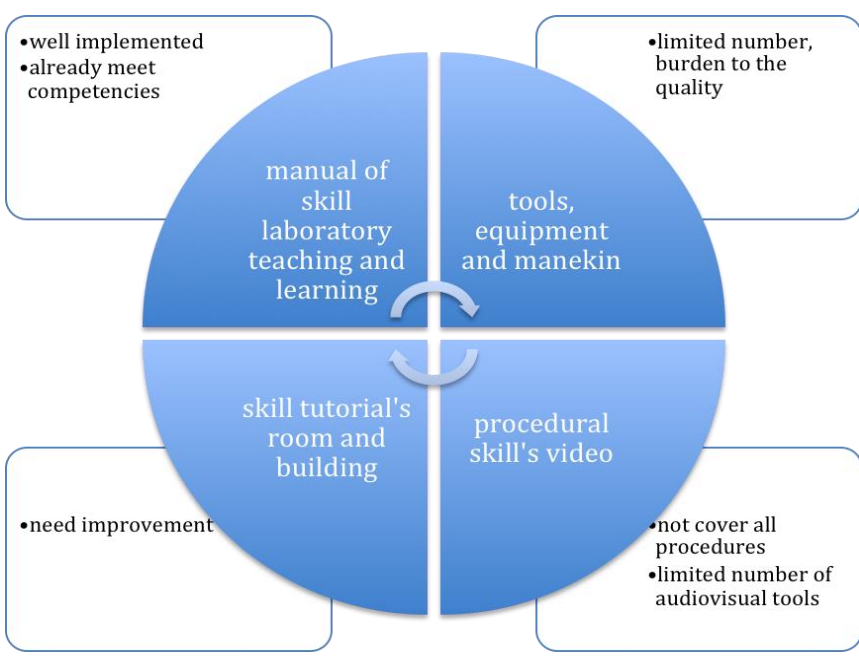

Fig. 1. The problems assessment model had found in our skill laboratory teaching and learning.

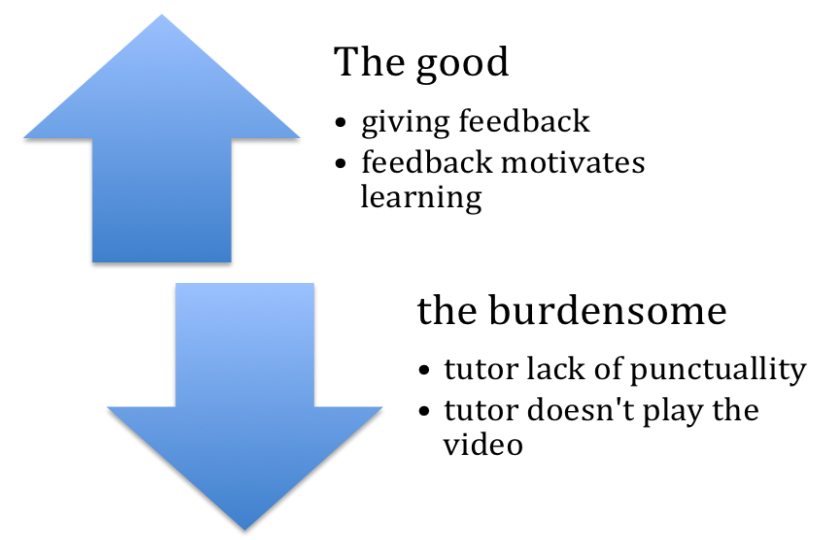

Fig. 2. The evaluation of tutor role as presented in the graphic

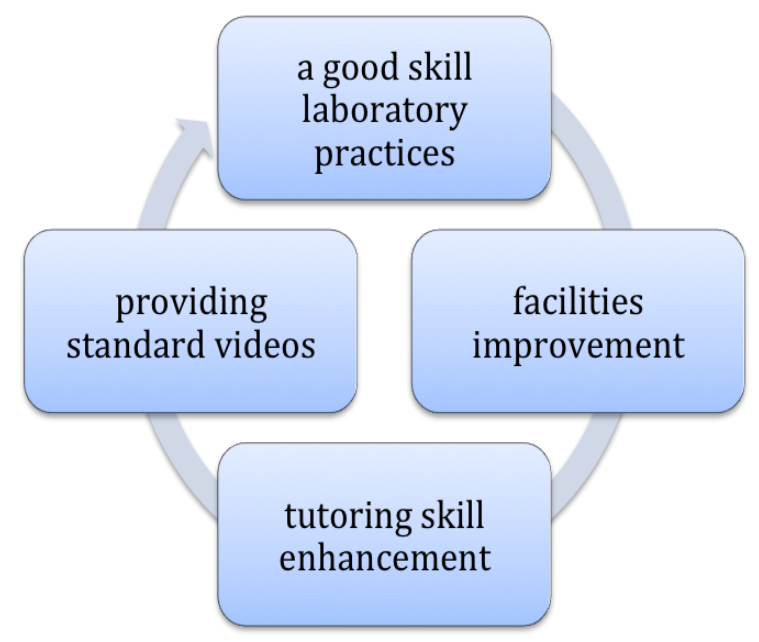

Fig. 3. A continuous model to implement a good skill laboratory teaching and learning based on our problems

\section{DISCUSSION}

Based on the result we can conclude that both student and tutor find that resource and facility are important factor to build a comfortable learning environment. A comfortable learning environment should include a clinical skills center in which students receive training in a systematic, safe and protected fashion using effective educational strategies appropriate to their specific needs and level of experiences [1]. As we already have clinical skill center/laboratory known as CSU, we still needs to improve the quantity and quality of building facilities. Our CSU building has already adequate size, readily accessible to major users, but not full provided with appropriate telecommunication links, audiovisual and computer facilities. Those needs are related to the financial burden, as our medical school is a public/state school that depend on the government financing system. 
For communication skills, we already have standardized patients (SP) to help student practicing their communication skill, as role playing technique [3]. Based on result, SP management is not the main problems in our setting. In this part, SP can be managed as teaching and assessment instruments well in our faculty.

As we know that medical teacher is not only lecturer, but they also have twelve roles as medical teacher [4]. Their role in the clinical skill laboratory not just tutor but also includes information provider, role model, facilitator, student assessor, resource material creator and study guide producer [4,5]. That is why, tutor should be professional, as lecturer and many others' role. In Fig. 2 we can assumed that our tutor should be more professional, they should have more punctual habit, to optimize the time management during skill laboratory learning. In our developed model, tutoring skill enhancement is an important part to make a continuous implementation of good skill laboratory practices (teaching and learning).

Tutor's feedback is also an important part to encourage student's motivation in learning, so giving feedback in tutor role for every skill's procedures is the part of tutor job [6].

From Fig. 3, in our model, we can see a continuing process to reach a good skill laboratory practices (teaching and learning). The good skill laboratory practices should have a proper supporting facility, the facility should meet every skill procedures' competency [2]. To complete the facility we need more money, but we have financial management burden, so we can find some grant or make minor renovation only to make more clean and comfortable facility without make its sophisticated. After the facility is completed properly, the tutor skill in tutoring, teaching and others role as medical teacher should be enhanced. As the tutor already competent as medical doctor, our faculty only needs to enhance medical teacher competencies through many workshop our training [5]. Both workshop and training are not need much money, because we can develop a peer training, in example an internist teach other tutors to deliver insulin injection properly, or medical education staff member teach how to deliver skill teaching effectively. This model can minimize financial issues, because we don't need to have an 'expensive' expert.

The last part of our continuous model is making standardized video for all skills. This video can easy help student to have skill repetition by their own self as a part of self directed learning [1]. Many medical or nursing school use video in teaching clinical skill competencies $[2,7,8]$. Based on Fig. 2, our problem is limited to the number of audiovisual tools to play the video, but we can upload the video and make its online so student easier to watch wherever and whenever they goes. YouTube as a free channel in delivering video to others, can be a significant resource to make the video online. Duncan, et all (2012) had stated that YouTube could be a learning resources, however lecturer should guide what kind of video for student $[8,9]$.

Looking at our problems in Fig. 1 and 2, if we can implement our continuous model, we hope it can make our clinical skill laboratory teaching and learning become more ideal and better than before. But still tutor is essential part in teaching and learning. A passionate and professional tutor can be more valuable resources than any other sophisticated facility, because a tutor can be anything as medical teacher $[4,5]$.

\section{CONCLUSION}

Based on our model, there are three kind of improvement should be meet but still tutor is the central role to encourage the student in mastering the skill procedures.

\section{ACKNOWLEDGMENT}

Thank you to all staff of CSU of Medical Study Program of Faculty of Medicine and Health Sciences. This research is funded by grant from Center of publication and research of Syarif Hidayatullah State Islamic University (UIN) Jakarta .

\section{REFERENCES}

[1] Harden RM, Glas F, Frcsed F. A PRACTICAL GUIDE FOR MEDICAL Edited by. 2001.

[2] Kneebone R, Kidd J, Nestel D, Asvall S, Paraskeva P, Darzi A. An innovative model for teaching and learning clinical procedures. Med Educ. 2002;36(7):628-634. doi:10.1046/j.1365-2923.2002.01261.x.

[3] Barrows HS. An overview of the uses of standardized patients for teaching and evaluating clinical skills. AAMC. Acad Med. 1993;68(6):443-451. doi:10.1097/00001888-199306000-00002.

[4] Crosby RMHJ. AMEE Guide No 20: The good teacher is more than a lecturer - the twelve roles of the teacher. Med Teach. 2000;22(4):334-347. doi:10.1080/014215900409429.

[5] Lake FR. Teaching on the run tips Doctors as teachers 2. 2004;180(April):415-416.

[6] Driessen E, Overeem K, Tartwijk J Van. Learning from practice: mentoring, feedback and portfolios. In: Medical Education Theory and Practice. Churchill livingstone Elsevier; 2011:211228.

[7] Forbes H, Oprescu FI, Downer T, et al. Use of videos to support teaching and learning of clinical skills in nursing education: A review. Nurse Educ Today. 2016;42:53-56. doi:10.1016/j.nedt.2016.04.010.

[8] Duncan I, Yarwood-Ross L, Haigh C. YouTube as a source of clinical skills education. Nurse Educ Today. 2013;33(12):15761580. doi:10.1016/j.nedt.2012.12.013.

[9] May OW, Wedgeworth MG, Bigham AB. Technology in Nursing Education: YouTube as a Teaching Strategy. J Pediatr Nurs. 2013;28(4):408-410. doi:10.1016/j.pedn.2013.04.004. 